\title{
Leonardo Zamudio Villanueva
}

\author{
Felix Gil Orbezo
}

Received: 9 September 2013 / Accepted: 9 September 2013 /Published online: 13 October 2013

(C) Springer-Verlag Berlin Heidelberg 2013

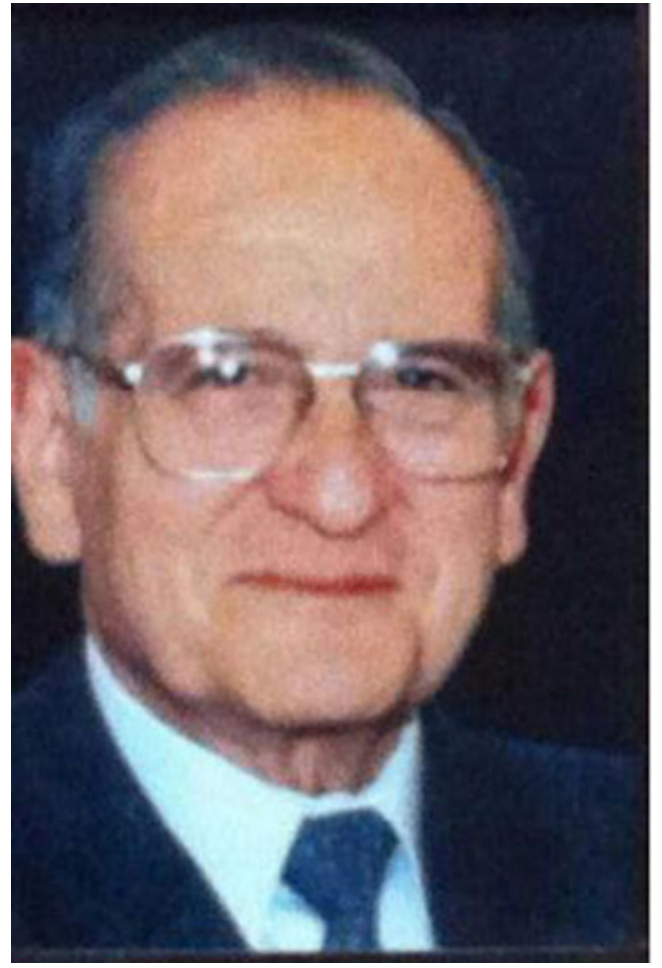

FIRST LATIN AMERICAN SICOT PRESIDENT

(1926-2013)

Born in Morelia, Michoacán, México, in 1926, Leonardo Zamudio came to be one of the most prestigious doctors in Mexico.

F. G. Orbezo $(\square)$

Hospital Español de México, Mexico City, México

e-mail: gilfelix@prodigy.net.mx

URL: www.sicot.org
Outstanding at all stages of his life, Leonardo finished his college and medical studies with honours at the Faculty of Medicine, Universidad Autonoma de Mexico and continued his training in Santa Rosa Hospital and Robert B Green Memorial Hospital in San Antonio, Texas, USA.

Later he became Chief of Service at Escandon Hospital, Conde de Valenciana Hospital and Hospital Español de Mexico.

He published more than 114 scientific articles in national and international journals. He was also author and editor of several books on orthopaedics and translator of more than 20 books and magazines related to orthopaedics.

His professional life has been long, productive and very successful, with an extensive range of interests. He belonged to 19 national and international societies and received more than 18 national and international distinctions awarded by the academies and societies with whom he enthusiastically collaborated.

$\mathrm{He}$ also ventured into the realms of literature and successfully edited 13 books with poems, humour, love, medical and political anecdotes, of highly enjoyable reading.

As a teacher, he collaborated in pre- and post-graduate studies, with the main universities of Mexico, and inspired many generations of orthopaedic surgeons.

In order to enable young orthopaedic trainees to find somewhere to update their knowledge, he founded and funded the Metropolitan Library of Orthopaedics and Traumatology, which contains an extensive range of books and worldwide publications.

Again, on behalf of the new generations, as president of XI SLAOT Congress (Latin American Society of Orthopaedics and Traumatology), he initiated the sponsorship of numerous fellowships for young surgeons, which are still awarded. Furthermore, he also personally sponsored 52 fellowships (20 international), for countries such as India, England, China, 
Chile, Bulgaria, Belgium, Serbia, Iran, Spain, Argentina, and also for Mexican nurses and students.

His talents as a great organiser, administrator and his unique reputation led to his election to several major positions in national and international societies.

In 1990, due to his active participation in SICOT since 1960, he achieved the presidency, becoming the first LatinAmerican orthopaedic surgeon to be distinguished with this honorable position, a matter of enormous pride to the LatinAmerican Orthopaedic Community. During his presidency he paid close attention to a balanced representation of all areas of the world within SICOT, especially from the less developed countries. He encouraged the rapprochement through the scientific congress of what at that time were called the East and West countries. He contributed to the development of the SICOT Education Programmes and personally sponsored the Pillar Zamudio Fellowship devoted solely to female orthopaedic surgeons. Very humble and human, he would not tolerate conceited behaviour.
Over and above his professional success, as a man of faith and incredible social conscience, he personally assisted world missions to eradicate polio around the globe, and dedicated many hours of his life to the treatment of Hansonian (leprosy) patients.

He was a constant reader, creative writer, a lover of cultures and an eager student of other languages.

As a strong supporter and promoter of SICOT, he believed SICOT's true essence (very different from other international societies) proposed not only science and innovative techniques, but a rich and deep knowledge of real medicine around the world. The great experience of getting to know not only extraordinary doctors but outstanding humans, eager to establish real bridges of understanding and long-lasting friendships between them and their countries.

Leonardo Zamudio....... ma man to remember!

Felix Gil Orbezo

Mexican National Delegate 